\title{
Infrared Spectroscopic and Modulated Differential Scanning Calorimetric Study of Physical Aging in Bisphenol A Polycarbonate
}

\author{
Jin LU, ${ }^{\dagger}$ Yong WANG, and Deyan SHEN \\ Institute of Chemistry, Academic Sinica, \\ Beijing 100080, China
}

(Received February 28, 2000)

\begin{abstract}
FT-IR spectroscopy was used to examine conformational changes in the quenched Bisphenol A Polycarbonate (BPAPC) films during physical aging. It was observed that the amount of energy favored trans-trans conformers increased, while energy less favored trans-cis conformers decreased upon sub- $T_{\mathrm{g}}$ annealing. Since the trans-trans conformers allow closer local packing of the polymer chains than the trans-cis conformers do, the results may indicate that sub- $T_{\mathrm{g}}$ annealing will lead to closer interchain packing. In situ FT-IR studies on the conformational changes of BPAPC films with different thermal histories, i.e., quenched from the rubbery and sub- $T_{\mathrm{g}}$ annealed for different time, were carried out while increasing the temperature through the glass transition region. The temperature dependencies of the infra-red spectra show that incremental changes of the population of trans-cis conformers in the quenched sample are gradual, while rather abrupt changes occur in the sub- $T_{\mathrm{g}}$ annealed samples. The magnitude and temperature of the abrupt changes of trans-cis conformers are related with the time of the sub- $T_{\mathrm{g}}$ annealing. The energy absorbed during the abrupt conformational change represents only part of the energy of the endothermic peak observed by modulated differential scanning calorimetry. The results are explained in terms of the formation of new cohesional entanglements during sub- $T_{g}$ annealing.

KEY WORDS Bisphenol A Polycarbonate / Physical Aging / Sub- $T_{\mathrm{g}}$ Annealing / Conformations / Infra-Red Spectroscopy /
\end{abstract}

It is well known that annealing amorphous polymers in a temperature range below their glass transition temperature $\left(T_{\mathrm{g}}\right)$ will result in changes in their structure and properties. This phenomenon, which is known as physical aging, ${ }^{1-4}$ occurs because an amorphous material at a temperature below $T_{\mathrm{g}}$ is in a glassy, nonequilibrium state which, on annealing at constant temperature, will approach with time an equilibrium state at that temperature. The physical aging yields remarkable changes in the mechanical properties of polymers, such as embrittlement, decrease in yield strength and changes in creep and stress relaxation, so accurate prediction of changes in physical properties with aging can have significant economic implications. However, the description and prediction of physical aging effects met with much difficulty caused by their nonlinear and nonexponential characters. ${ }^{5-8}$ Understanding of the physical aging on a molecular level is too poor to be of much help. Many investigators have suggested that aging is a completely morphological effect, that is, a result of the polymer chains attempting to reach an equilibrium, low energy conformation. It will be interesting to study the changes of conformational structure of the polymer chain and inter-chain packing during physical aging. Recent studies have employed such techniques as Nuclear Magnetic Resonance (NMR), ${ }^{9,10}$ Electron Microscopy $(\mathrm{EM})^{12,13}$ and Raman Spectroscopy ${ }^{14}$ to determine the polymeric structure before and after the aging process. In this work, we employed Fourier transform infrared (FT-IR) spectroscopy, which is sensitive to conformational structure, to monitor the change of conformation during physical aging of bisphenol A polycarbonate (BPAPC). In order to study the changes of interchain packing during physical aging, we further conducted modulated differential scanning calorimetry (MDSC) and in situ FT-IR experiments.

It is well established that physical aging is a relaxation process, and the main thermodynamic parameters that change with time are the volume and the enthalpy, provoking changes in many physical properties of the polymer (i.e., mechanical ${ }^{1}$ or dielectric properties ${ }^{15,16}$ ). Differential scanning calorimetry (DSC) has traditionally been used to reveal enthalpy relaxation occurring near or below the $T_{\mathrm{g}}$ in amorphous polymers. However, the overlap of the glass transition and the enthalpy relaxation often makes the measurement of relaxation enthalpy and the interpretation difficult. Recently, a new thermal analysis technique ${ }^{17-20}$ modulated differential scanning calorimetry (MDSC) has been developed to provide not only the "total" heat flow obtained from conventional DSC, but also separates the total heat flow into two parts: the heat flow from the heat capacity effect (reversing) that usually comes from glass transition relaxation or crystal melting; and the heat flow from the nonheat capacity effect (nonreversing) that usually comes from enthalpic relaxation or cold crystallization. As a result, the relaxation enthalpy can be obtained directly from the nonreversing heat flow. Therefore, MDSC is very suitable for the study of physical aging in polymers. Many papers ${ }^{21-23}$ have reported that the sub- $T_{\mathrm{g}}$ annealed specimen shows an endothermic peak close to $T_{\mathrm{g}}$ in the DSC curve, and the magnitude and temperature

\footnotetext{
${ }^{\dagger}$ Present address: Fiber and Polymer Science Program, North Carolina State University, Campus Box 8301, Raleigh, North Carolina 27695-8301, U.S. A. (E-mail: jlu5@unity.ncsu.edu).
} 
of the peak increase with increasing annealing time and temperature. In this work, we observed the similar phenomena during physical aging of BPAPC by MDSC and obtained the relaxation enthalpy data directly. However, our understanding of these phenomena on a molecular level is rather limited. Thus we further conducted in situ FT-IR studies on the conformational changes of BPAPC films with different thermal histories: quenched from the rubbery and sub- $T_{\mathrm{g}}$ annealed for different time. It was found that incremental changes of the population of trans-cis conformers in the quenched sample are gradual, while abrupt changes occur in the sub- $T_{\mathrm{g}}$ annealed samples. Comparing the energy absorbed during the abrupt conformational change with the energy of the endothermic peak observed by MDSC for the annealed sample, we can get some clue of the changes of interchain packing during physical aging.

\section{EXPERIMENTAL}

Amorphous BPAPC films of about $3 \mu \mathrm{m}$ thickness were prepared by solution casting of a $5.0 \%$ solution of BPAPC in chloroform onto glass plates at room temperature. The cast films were air dried and then dried in vacuum at $60^{\circ} \mathrm{C}$ for $72 \mathrm{~h}$ to remove residual solvent. The dried films were heated to $170^{\circ} \mathrm{C}$ for $15 \mathrm{~min}$ and rapidly quenched into ice water to get the rubbery-quenched sample $\mathrm{Q}$, and then they were annealed at $127^{\circ} \mathrm{C}$ for different time to get the sub- $T_{\mathrm{g}}$-annealed samples.

Infrared spectra were recorded on a Perkin-Elmer System 2000 FT-IR instrument under standard operating conditions. For room temperature measurements each spectrum was the average of 32 scans at a resolution of $4 \mathrm{~cm}^{-1}$. For measurements during a temperature scan from $126^{\circ} \mathrm{C}$ to $158^{\circ} \mathrm{C}$, the specimen was held in the heating cell, the heating rate being $1^{\circ} \mathrm{C} \mathrm{min}^{-1}$. The spectra were taken every $2^{\circ} \mathrm{C}$ increase, and each spectrum was the average of 20 scans. The measurement time per each spectrum was about $50 \mathrm{~s}$. Selected IR bands were resolved using a peak fitting program (LCC) to determine the area under the peak, the bands were assumed to be Gaussian with a linear baseline.

Thermal characteristics of samples were determined with a TA 2910 MDSC. In MDSC, a sinusoidal temperature change is superimposed on the normal temperature program, which will result in a cyclic heating profile. Deconvolution of the resultant heat flow profile during this cyclic heating provides not only the "total" heat flow obtained from conventional DSC, but also separates that total heat flow into its reversing (glass-transition) and non-reversing (enthalpy relaxation) components. Thus the relaxation enthalpy can be calculated using the nonreversing heat flow signal. Samples of 5-10 mg were used in this test. A heating rate of $5^{\circ} \mathrm{C} \min ^{-1}$ was employed from $70^{\circ} \mathrm{C}$ to $200^{\circ} \mathrm{C}$ with temperature modulation amplitude of $1^{\circ} \mathrm{C}$ and an oscillation period of $40 \mathrm{~s}$ throughout this investigation. Both temperature and baseline were calibrated as in conventional DSC. Nitrogen was used as purge gas. In all the thermograms presented, endothermic signals are downward pointing.
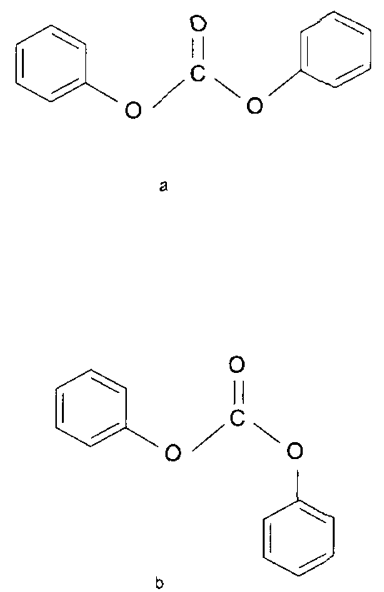

Figure 1. Possible conformations of diphenyl carbonate: (a) trans-trans and (b) trans-cis.

\section{RESULTS AND DISCUSSION}

The $-\mathrm{C}_{6} \mathrm{H}_{4}-\mathrm{O}-\mathrm{CO}-\mathrm{O}-\mathrm{C}_{6} \mathrm{H}_{4}-$ moiety (diphenyl carbonate group) of a BPAPC chain shows trans-trans and trans-cis conformers through the rotations of the phenyl group (see Figure 1). P. Schmidt et al. ${ }^{24}$ found that both trans-trans and trans-cis conformational structures are present in the amorphous phase, and further performed the infrared spectroscopic characterization of contributing conformers of the BPAPC. The bands at $1223 \mathrm{~cm}^{-1}$ and $1252 \mathrm{~cm}^{-1}$ have been assigned to $\mathrm{C}-\mathrm{O}-\mathrm{C}$ antisymmetric vibration in the trans-cis and trans-trans conformers separately. The higher-frequency component of the carbonyl band corresponds to energetically less favored structure trans-cis conformer, while the lowerfrequency component of the carbonyl band is due to energetically favored structure trans-trans conformer. All these bands are sensitive to conformational structure. So we can use these four bands to observe the conformational changes during physical aging. Since there is overlap of the trans-trans characteristic bands lowerfrequency of carbonyl band and $1252 \mathrm{~cm}^{-1}$ with transcis characteristic bands higher-frequency of carbonyl band and $1223 \mathrm{~cm}^{-1}$, we use the difference spectra to observe the conformational changes during physical aging process.

Samples of solution-cast amorphous BPAPC films with different thermal history, one being quenched in ice water from $170^{\circ} \mathrm{C}(\mathrm{Q})$, others being annealed at $127^{\circ} \mathrm{C}$ for different time, were analyzed by Fourier transform IR spectroscopy at room temperature. Figure 2 shows the difference spectra of $\mathrm{QA} 1-\mathrm{Q}$ and $\mathrm{QA2}-\mathrm{Q}$, where $\mathrm{QA} 1$ is the sample that was annealed for $32 \mathrm{~h}, \mathrm{QA} 2$ is the sample that was annealed for $96 \mathrm{~h}$. From the difference spectra, we can see that the $1772 \mathrm{~cm}^{-1}$ (lower-frequency of carbonyl band) and $1252 \mathrm{~cm}^{-1}$ bands associated with the trans-trans conformation are both positive, and 1781 $\mathrm{cm}^{-1}$ (higher frequency of carbonyl band) and $1223 \mathrm{~cm}^{-1}$ bands associated with the trans-cis conformation are both negative. The intensities of these four bands for QA $2-\mathrm{Q}$ are stronger than those for $\mathrm{QA1}-\mathrm{Q}$. This indicates that the population of low-energy trans-trans conform- 


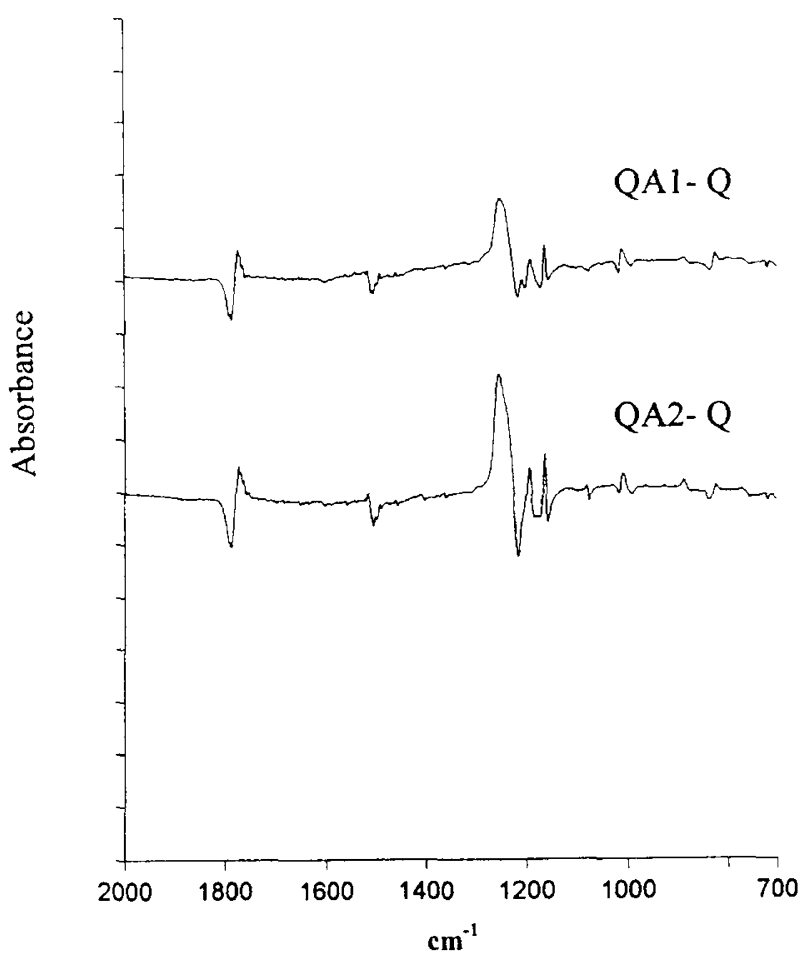

Figure 2. Difference spectra of samples $Q A 1-Q$ and $Q A 2-Q$, where $\mathrm{Q}$ is the sample quenched from rubbery state, QA1 and QA2 are the samples annealed at $127^{\circ} \mathrm{C}$ for $32 \mathrm{~h}$ and $96 \mathrm{~h}$ separately.

ers increases, while the population of high-energy transcis conformers decreases upon sub- $T_{\mathrm{g}}$ annealing. This is supported by the X-ray results. ${ }^{11}$ Figure 2 also shows that the increase of absorbance of the $1781 \mathrm{~cm}^{-1}$ band is similar to the decrease of absorbance of the $1772 \mathrm{~cm}^{-1}$ band, which indicates that the absorptivity ratio of the 1781 and $1772 \mathrm{~cm}^{-1}$ bands is close to 1 . However for doublet $1252 / 1223 \mathrm{~cm}^{-1}$, it is complicated due to the overlap with 1194 and $1163 \mathrm{~cm}^{-1}$ bands. So we choose 1781 and $1772 \mathrm{~cm}^{-1}$ two bands as the key bands for determining the relative conformational population. Since these two peaks were not well resolved for quantitative analysis, we employed curve fitting procedure to separate them. Since from the difference spectrum we knew that the $1781 \mathrm{~cm}^{-1}$ and $1772 \mathrm{~cm}^{-1}$ bands can be assigned to trans-cis and trans-trans conformations seperately, we curve fitted the original band contour with fixing the positions of these two components at 1781 and $1772 \mathrm{~cm}^{-1}$. We found out that a Gaussian profile, rather than a Lorentzian band shape, leads to a better fit of the spectra. Therefore, by assuming the bands were Gaussian with a linear baseline, all the spectra in this region were curve fitted with fixed peak position to determine the area under the peaks, as is shown in Figure 3 . Thus the fraction of trans-trans $\left(f_{\mathrm{T}-\mathrm{T}}\right)$ and trans-cis $\left(f_{\mathrm{T}-\mathrm{C}}\right)$ conformers can be obtained by

$$
f_{\mathrm{T}-\mathrm{T}}=\frac{S_{1772}}{S_{1772}+S_{1781}}
$$

and

$$
f_{\mathrm{T}-\mathrm{C}}=\frac{S_{1781}}{S_{1772}+S_{1781}}
$$

The changes in the percent trans-trans conformers $v$.

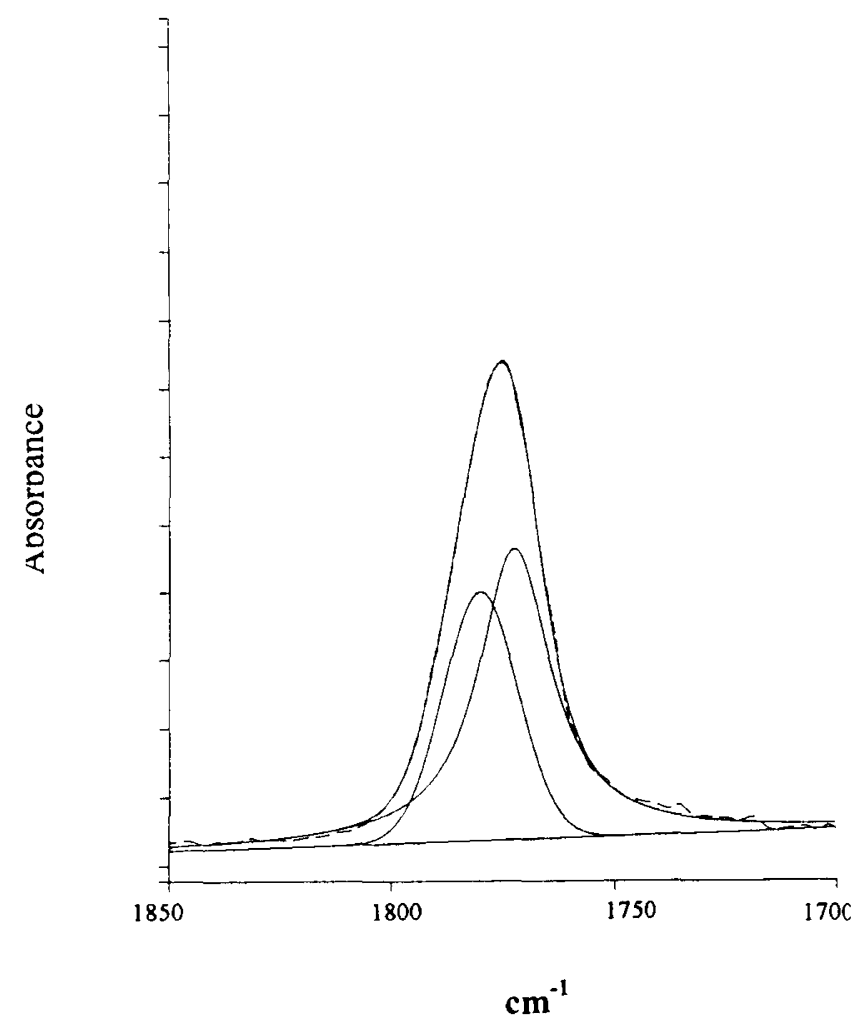

Figure 3. Curve fitting of the IR spectra in the region between 1700 and $1850 \mathrm{~cm}^{-1}$. Dotted spectrum is the original band contour. Solid spectra are the curve-fitted band contour and its components.

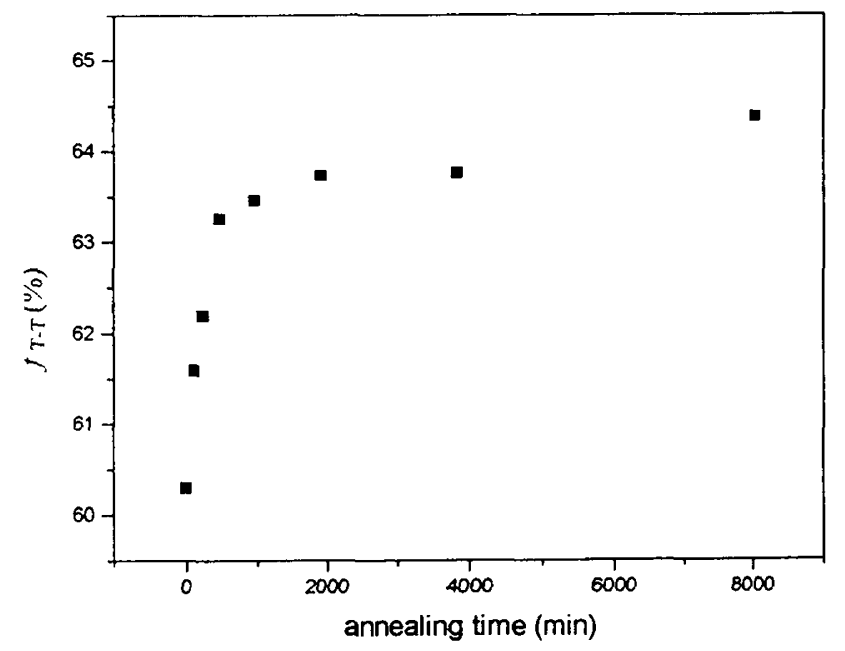

Figure 4. Changes of the percentage of trans-trans conformers of quenched sample as a function of annealing time at $127^{\circ} \mathrm{C}$.

sub- $T_{\mathrm{g}}$ annealing time of the BPAPC films were shown in Figure 4. It is clear that the conformational state frozen at $170^{\circ} \mathrm{C}$ in the sample $\mathrm{Q}$ has more high-energy trans-cis conformers, and the percentage of trans-trans conformers increases with increasing annealing time and starts to level off after about $20 \mathrm{~h}$. The quenched sample is known to be a nonequilibrium state. Sub- $T_{g}$ annealing of the quenched amorphous sample will bring it to a state closer to the equilibrium state accompanied by changes in the interchain aggregation and the longrange chain conformational structure. The conformational state frozen at higher temperature in sample $Q$ has more high-energy trans cis conformers, but less low- 


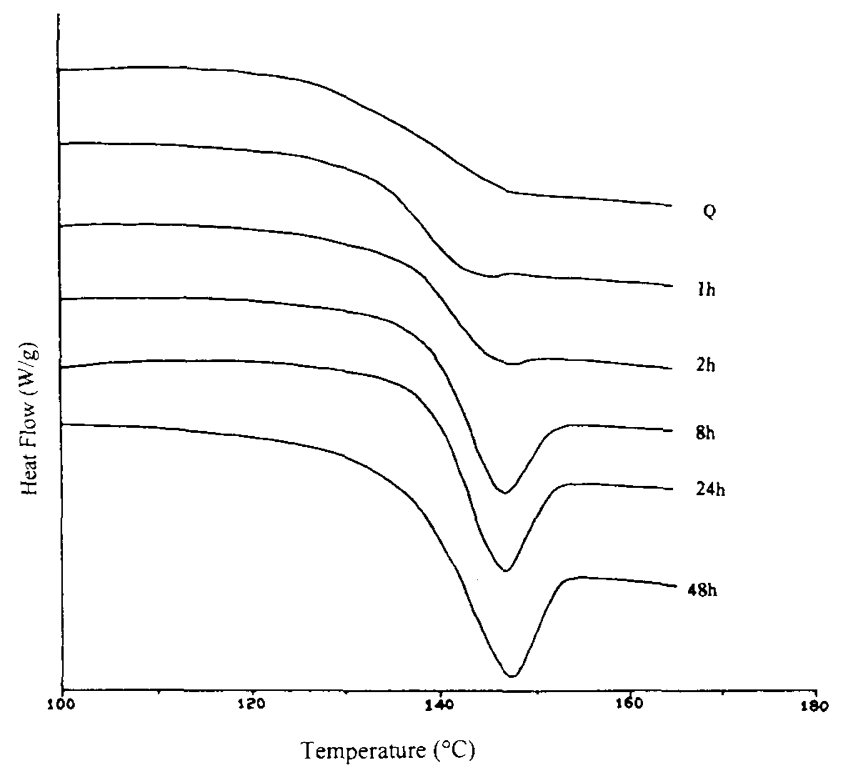

Figure 5. Total heat flow MDSC curves obtained at $5^{\circ} \mathrm{min}{ }^{1}$ for the rubbery quenched BPAPC samples with different thermal history (annealed at $127^{\circ} \mathrm{C}$ for $0 \mathrm{~h}, 1 \mathrm{~h}, 2 \mathrm{~h}, 8 \mathrm{~h}, 24 \mathrm{~h}$ and $48 \mathrm{~h}$ ).

energy trans-trans conformers. The percentage of trans -trans conformers increases with annealing time during transition to the state closer to equilibrium.

The MDSC total heat flow curves for the quenched sample $\mathrm{Q}$ and the sub- $T_{\mathrm{g}}$ annealed at $127^{\circ} \mathrm{C}$ for $1 \mathrm{~h}, 2 \mathrm{~h}$, $8 \mathrm{~h}, 24 \mathrm{~h}$, and $48 \mathrm{~h}$ samples are shown in Figure 5 . The total heat flow curve shows the sum of all the thermal response of the sample and provides the same level of information as in normal DSC. From the figure, we can see that the quenched sample shows a step-like increase of enthalpy during heating up across $T_{\mathrm{g}}$, however, the sub$T_{\mathrm{g}}$ annealed samples display an endothermic peak around $T_{\mathrm{g}}$. The endothermic peak increased in magnitude and shifted to higher temperatures with increasing annealing time. Since MDSC can separate the total heat flow into two parts: reversing (glass-transition) and nonreversing (enthalpy relaxation) components, we can obtain the accurate relaxation enthalpy $(\Delta H)$ directly from the non-reversing heat flow. The results are listed in Table I. From this table, we can see that the magnitude of enthalpy relaxation increases with the aging time.

In order to understand this phenomenon on a molecular level, in situ FT-IR measurements were carried out to see what conformational changes could be observed for the BPAPC films with different thermal history. On heating up at $1^{\circ} \mathrm{C} \min ^{-1}$ from $126^{\circ} \mathrm{C}$ to $158^{\circ} \mathrm{C}$ through $T_{\mathrm{g}}$, the temperature dependencies of the infra-red spectra for BPAPC films with different thermal history were measured. The spectra were taken every $2^{\circ} \mathrm{C}$ increase in temperature. The difference spectra were obtained by subtraction of every other adjacent spectrum. Figure 6 shows the temperature difference spectra for every $4^{\circ} \mathrm{C}$ increase in temperature of the samples: (a) quenched, (b) annealed at $127^{\circ}$ for $48 \mathrm{~h}$ and (c) annealed at $127^{\circ} \mathrm{C}$ for $120 \mathrm{~h}$. With the increase of the temperature, the 1223 $\mathrm{cm}^{-1}$ and $1781 \mathrm{~cm}^{-1}$ bands associated with the trans - cis conformation increased, but the $1252 \mathrm{~cm}^{-1}$ and 1772 $\mathrm{cm}^{-1}$ bands associated with the trans-trans conformation decreased. This indicates that the conformation of
Table I. Relaxation enthalpy of BPAPC samples during physical aging

\begin{tabular}{lc}
\hline \multicolumn{1}{c}{ Samples } & Relaxation enthalpy $\Delta H /\left(\mathrm{J} \mathrm{g}^{1}\right)$ \\
\hline Quenched from rubbery state & 0 \\
Sub- $T_{\mathrm{g}}$ annealed for $1 \mathrm{~h}$ & 1.01 \\
Sub- $T_{\mathrm{g}}$ annealed for $2 \mathrm{~h}$ & 1.15 \\
Sub- $T_{\mathrm{g}}$ annealed for $8 \mathrm{~h}$ & 2.11 \\
Sub- $T_{\mathrm{g}}$ annealed for $24 \mathrm{~h}$ & 2.40 \\
Sub- $T_{\mathrm{g}}$ annealed for $48 \mathrm{~h}$ & 3.01 \\
\hline
\end{tabular}

BPAPC films will change from low-energy trans-trans conformation into high-energy trans-cis conformation with the increase of the temperature. For quenched sample, this rate of transition is similar, only a little higher above $T_{\mathrm{g}}$ (in the region $142^{\circ} \mathrm{C}$ to $158^{\circ} \mathrm{C}$ ). However, for annealed samples, the rate of transition is highest in the glass transition region $\left(142-146^{\circ} \mathrm{C}\right)$. In order to observe this phenomenon more clearly, the changes of the population and rates of increase of trans-cis conformers as a function of temperature from measured $S_{1772}$ and $S_{1781}$ were calculated. Figure 7 shows the rates of increase in trans-cis conformers as a function of temperature for these samples. The increase in the fraction of trans ${ }^{-}$cis conformers went gradually for quenched sample, while abrupt conformational changes occurred in the sub- $T_{\mathrm{g}}$ annealed samples. The magnitude and temperature of the abrupt changes of the fraction of trans-cis conformers depend on the time of sub- $T_{\mathrm{g}}$ annealing. It is interesting to see that the shapes of the curves closely resemble the reverse of MDSC curves for all the samples. However, comparing the MDSC curve (see Figure 5) with FTIR result (see Figure 7b) of the sample annealed at 127 ${ }^{\circ} \mathrm{C}$ for $48 \mathrm{~h}$, it was found that the endothermic peak of MDSC curve occurred at higher temperature $\left(147^{\circ} \mathrm{C}\right)$ than the peak in the rates of trans-cis conformational population $\left(144^{\circ} \mathrm{C}\right)$. This maybe because the heating rate in MDSC measurement $\left(5^{\circ} \mathrm{C} \min ^{-1}\right)$ is faster than that in IR measurement $\left(1^{\circ} \mathrm{C} \min ^{-1}\right)$.

It is interesting to determine the energy absorbed during the conformational abrupt changes. The experimental value of $0.46 \mathrm{kcal} \mathrm{mol}^{-1}$ or $7.57 \mathrm{~J} \mathrm{~g}^{-1}$ was obtained ${ }^{24}$ for the energy difference between the trans-cis and the trans-trans conformation. For the sample annealed at $127^{\circ} \mathrm{C}$ for $48 \mathrm{~h}$, the increment of population of trans-cis conformers from $140^{\circ} \mathrm{C}$ to $150^{\circ} \mathrm{C}$ is $2.0 \%$. So the energy absorbed during the step conformational change is 0.15 $\mathrm{J} \mathrm{g}^{-1}$. However, the relaxation enthalpy in the MDSC measurement of this sample was $3.01 \mathrm{~J} \mathrm{~g}^{-1}$ (see Table I). Therefore, the energy absorbed during the abrupt conformational changes contributes some, but only small amount of the energy of the endothermic peak in the MDSC measurement.

Recently Qian ${ }^{25-28}$ has put forward the concept of cohesional entanglement of neighboring chain segments, a kind of interchain cohesion (attractive interaction) with local parallel alignment of neighbouring chain segments as physical crosslinks. When these cohesional entanglements lock up the long-range cooperative conformational changes of the chain that are necessary for rubber elasticity, the polymer exhibits glassy state properties. At temperatures higher than $T_{\mathrm{g}}$, the cohesional entanglement spacing is necessary greater than the length of 


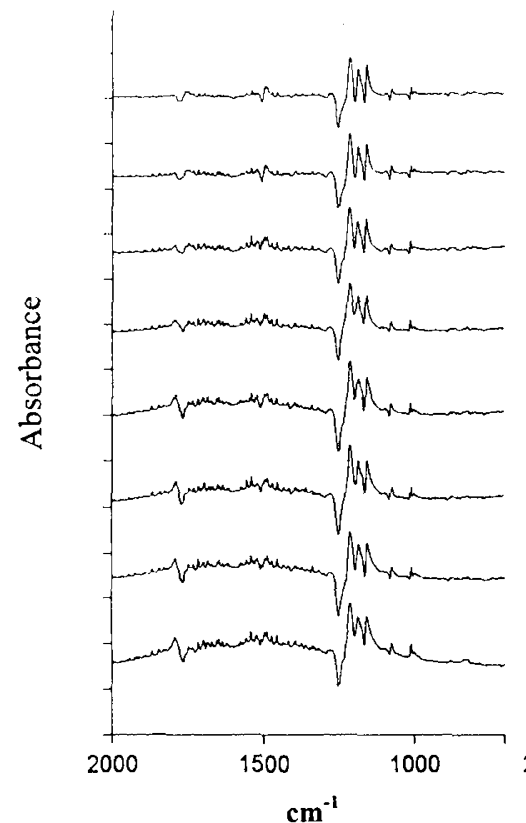

(a)

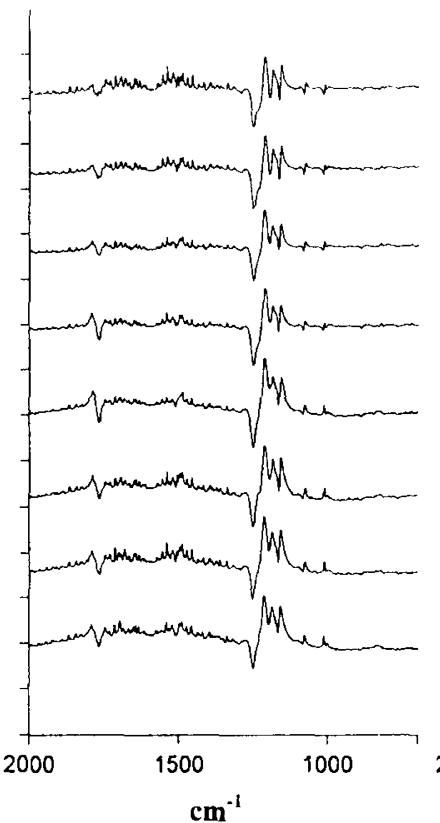

(b)

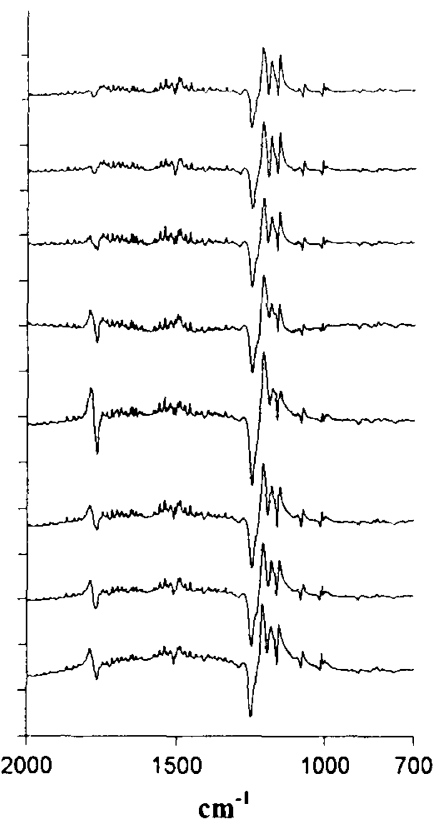

(c)

Figure 6. The temperature difference spectra for every $4^{\circ} \mathrm{C}$ temperature increase from $126^{\circ} \mathrm{C}$ to $156^{\circ} \mathrm{C}$ of the samples: (a) quenched from rubbery state, (b) annealed at $127^{\circ} \mathrm{C}$ for $48 \mathrm{~h}$ and (c) annealed at $127^{\circ} \mathrm{C}$ for $120 \mathrm{~h}$.
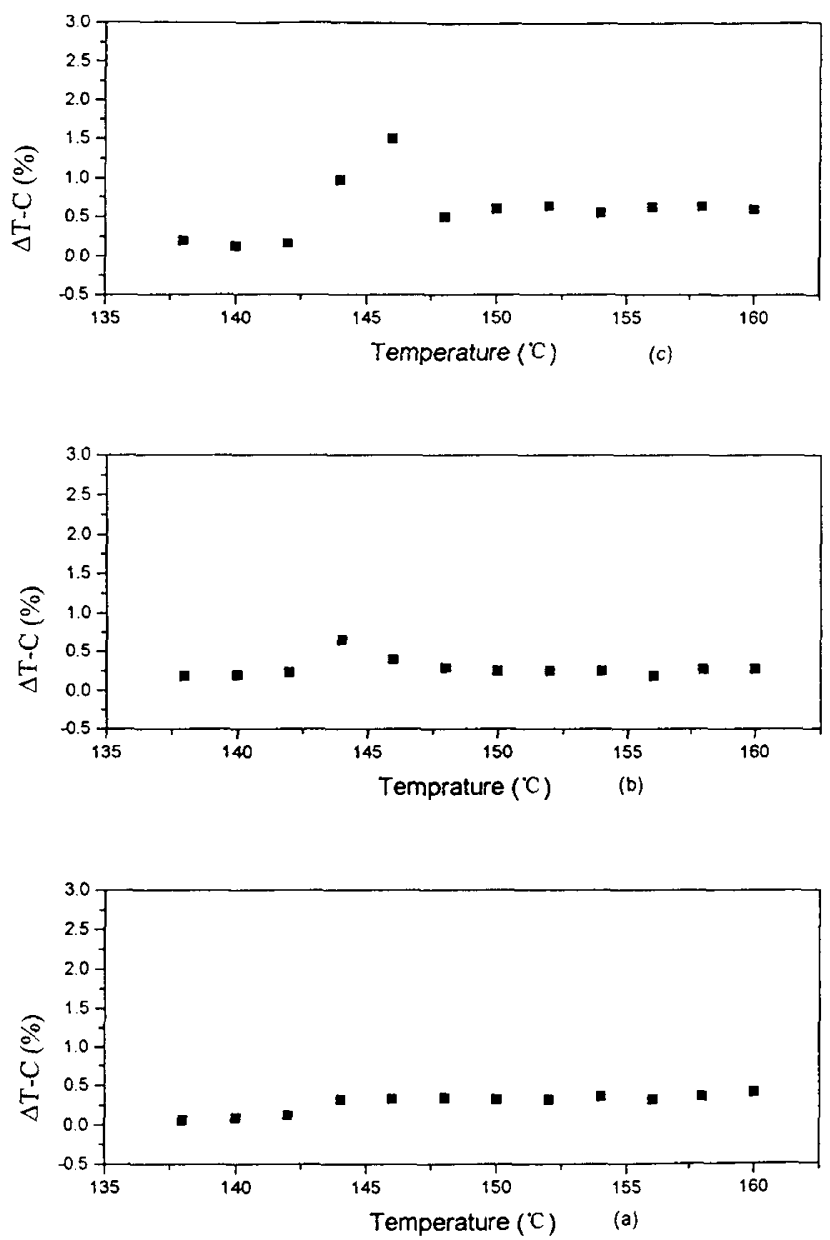

Figure 7. Changes of the rate of increase of trans-cis conformers as a function of temperature for the samples: (a) quenched from rubbery state, (b) annealed at $127^{\circ} \mathrm{C}$ for $48 \mathrm{~h}$ and (c) annealed at $127^{\circ} \mathrm{C}$ for $120 \mathrm{~h}$. chain segment motion needed for rubbery elasticity. Rapid quenching of the samples from the rubbery state to temperatures below $T_{\mathrm{g}}$ does not allow sufficient time for the quenched sample to form new cohesional entanglements along the chain. Sub- $T_{\mathrm{g}}$ annealing will lead to the increase of the trans-trans conformation, which allows more local parallel alignment of neighboring chain segments. This may result in the formation of new cohesional entanglements along the chain. When the linear density of cohesional entanglement along the chain is high, they will hinder the conformational changes in some locations along the chain in the glassy state. Heating the sample to a temperature around $T_{\mathrm{g}}$, some cohesional entanglements are disentangled. The breaking of the cohesional entanglement leads to a sudden conformational change and absorption of heat as manifested in an endothermic peak in the MDSC curve. The number and the binding energy of the cohesional entanglements formed during sub- $T_{\mathrm{g}}$ annealing should depend on the duration of annealing. The longer the sub- $T_{\mathrm{g}}$ annealing time is, the more the binding energy of the cohesional entanglements is.

\section{CONCLUSION}

In summary, we have found that the conformation of BPAPC films will change from high-energy trans-cis conformation into low-energy trans-trans conformation gradually upon sub- $T_{\mathrm{g}}$ annealing. For the sub- $T_{\mathrm{g}}$ annealed samples, there is an abrupt change of the population of trans-cis conformers with the temperature in the glass transition region. However, the energy absorbed during the abrupt conformational change represents only part of the energy of the endothermic peak observed by modulated DSC. Therefore, based on the concept of cohesional entanglement of neighboring chain segments in the condensed state suggested by Qian ${ }^{25-28}$, 
we come to the conclusion that some new cohesional entanglements may be formed during the physical aging.

\section{REFERENCES}

1. L. C. E. Struik, "Physical Aging in Amorphous Polymers and Other Materials". Elsevier, Amsterdam, 1978.

2. S. Matsuoka, "Relaxation Phenomena in Polymers", Hanser, New York, N. Y., 1992.

3. I. M. Hodge, J. Non-Cryst. Solids, 169, 211 (1994).

4. J. M. Hutchinson, Prog. Polym. Sci., 20, 703 (1995).

5. K. L. Ngai and G. B. Wright, J. Non-Cryst. Solids, 131 (1991).

6. K. L. Ngai, E. Riande, and G. B. Wright, J. Non-Cryst. Solids, 172 (1994)

7. C. A. McKenna and G. B. McKenna, J. Res. Natl. Inst. Stand. Technol., 98, 523 (1993).

8. I. M. Hodge, Science, 267, 1945 (1995).

9. J. Schaefer, E. O. Stejskal, D. Perchak, J. Skolnick, and R. Yaris., Macromolecules, 18, 368 (1985).

10. M. P. Henrichs and V. A. Nicely, Macromolecules, 24, 2506 (1991).

11. E. Turska, J. Hurek, and L. Zmudzinski, Polymer, 20, 321 (1979).

12. M. G. Wyzgoski and G. S. Y. Yeh, Int. J. Polymeric Mater., 3, 133 (1974).

13. W. Frank, H. Goddarand, and H. A. Stuart, Polymer Letters.,
5, 711 (1967).

14. V. Stolarski, A. Letton, S. N. Lee, and J. Laane, Polym. Mater. Sci. and Eng., 71, 479 (1994).

15. T. Ricco and T. L. Smith, Polymer, 26, 1979 (1985).

16. S. Matsuoka, G. Williams, G. E. Johnson, and E. W. Anderson, Macromolecules, 18, 2652 (1985).

17. M. Reading, Trends Polym. Sci., 1, 248 (1993).

18. P. S. Gill, S. R Sanerbrunn, and M. Reading, J. Thermal. Anal., 40, 931 (1993).

19. M. Reading, A. Luget, and R. Wilson, Thermochim. Acta, 238, 295 (1994)

20. D. J. Hourston, M. Song, A. Hammiche, H. M. Pollock, and M. Reading, Polymer, 37, 243 (1996).

21. K. H. Illers, Makromol. Chem., 127, 1 (1969).

22. A. Gray and M. Gilbert, Polymer, 17, 44 (1976).

23. A. R. Berens and I. M. Hodge, Macromolecules, 15, 756 (1982).

24. P. Schmidt, J. Dybal, E. Turska, and A. Kulczycki, Polymer, 32, 1862 (1991).

25. R. Qian, "Macromolecules", H. Benoit and R. Rempp, Ed., Pergamon Press, Oxford, 1982, p 139.

26. R. Qian, L. Wu, D. Shen, D. H. Napper, R. A. Mann, and D. F. Sangster, Macromolecules, 26, 2950 (1993).

27. R. Qian, D. Shen, F. Sun, and L. Wu, Macromol. Chem. Phys., 197, 1485 (1996).

28. R. Qian, Macromol. Symp., 124, 15 (1997). 